\title{
Design Thinking na Educação
}

\section{Design Thinking in Education}

DUARTE, Anne Rosa; Bacharel; Universidade da Região de Joinville

annerosaduarte@gmail.com

\section{Resumo}

O presente trabalho relata uma experiência norteada pela cartilha da IDEO, intitulada Design Thinking para Educadores, com os alunos do 4을 ano da Escola de Educação Básica Francisco Zezuíno Vieira, no município de Laguna - Santa Catarina, a qual teve como intuito utilizar a abordagem do Design Thinking para colaborar com o processo de ensino-aprendizagem dos alunos. Esse processo resultou em um vídeo-documentário e um blog, os quais tiveram como objetivo tornar os conteúdos das aulas de História, Geografia e Ciências mais atraentes, promovendo, por conseguinte, a aproximação entre escola, pais e comunidade.

Palavras-chave: Design Thinking; Design Thinking para Educação; Ferramentas Pedagógicas.

\begin{abstract}
The present paper reports an experience guided by the booklet IDEO "Design Thinking for Educators" and carried out with students of the 4th year at E.E.B. School Francisco Zezuíno Vieira, in the city of Laguna, Santa Catarina State, in order to use the design thinking approach to work with the teaching and learning process of the students. This effort resulted a video documentary and a blog were developed, which have had as main purpose to make the contents of History, Geography and Science classes more attractive while promoting the approach between school, parents and community.
\end{abstract}

Keywords: Design Thinking; Design Thinking for Education; Pedagogical Tools. 


\section{Introdução}

A abordagem do Design Thinking não é nova, nem uma disciplina isolada, mas, sim, uma abordagem que auxilia a resolver problemas pautados em soluções centradas nos seres humanos nas mais diversas áreas (LOCKWOOD, 2010).

Particularmente na educação, o Design Thinking pode ter muito a contribuir, visto seu potencial inovador e transformador, que pode ter impacto nas formas tradicionais de ensinoaprendizagem, tornar as aulas mais dinâmicas e resolver situações através do olhar dos agentes diretamente envolvidos na dinâmica escolar (DT PARA EDUCADORES, 2014).

São características do Design Thinking: empatia; pensamento abdutivo; pensamento sistêmico; prototipação; iteração; colaboração; concentração no ser humano. Essas, por sua vez, incitam os designers thinkers a procurarem soluções que estejam alinhadas às necessidades humanas, que levem em consideração os recursos disponíveis, bem como suas restrições. (DI RUSSO, 2016, apud PEZZINI, 2016).

Tendo isso em vista, o presente trabalho procura trazer uma amostra de como o Design Thinking pode vir a ser um aliado na promoção de aulas mais interessantes, dinâmicas e construídas de maneira colaborativa. Os objetivos específicos concentraram-se em tornar as aulas de Ciências, Geografia e História, que no momento tratavam da Origem e Evolução do Universo e da vida, mais atraentes aos alunos, auxiliando-os a fixarem os conteúdos, promovendo, assim, a proximidade entre escola/pais/comunidade. Os objetivos foram alcançados por meio da produção de um vídeo em formato de documentário - no qual os alunos explicaram sobre a Origem do Universo, conforme a teoria do Big Bang, identificaram a localização do município de Laguna - SC no Mapa-múndi, além de explicarem sobre a Origem e Evolução da vida segundo a teoria de Charles Darwin - e da abertura de um blog, para que a escola publique conteúdos, atividades e notícias referentes às atividades escolares e, por meio dele, aproxime, assim, a escola dos pais e da comunidade.

Pautado pelas diretrizes do toolkit Design Thinking para Educadores, da empresa de consultoria IDEO, traduzido para o português pelo Instituto Educadigital, esta experiência se dividiu em cinco etapas: descoberta, na qual por meio da imersão pode-se ter uma visão dos problemas enfrentados pela escola e elencar possíveis possibilidades para uma intervenção; interpretação, na qual os dados coletados no processo de descoberta foram interpretados, e houve a escolha de um problema a ser solucionado; ideação, a qual tratou de gerar ideias; experimentação, na qual as ideias foram desenvolvidas e testadas; e evolução, que focou em analisar os feedbacks resultantes do trabalho.

\section{Design Thinking}

O Design Thinking é uma abordagem que tem como característica ser iterativa, empática, colaborativa, criativa e centrada no ser humano. Utiliza-se de métodos e ferramentas da área de conhecimento do Design para abordar problemas e buscar soluções inovadoras, pautada em processos empáticos, de ser humano para ser humano (LOCKWOOD, 2010).

A empresa de consultoria IDEO, fundada por David Kelley, foi a responsável pela disseminação do termo que ganhou bastante destaque nas empesas, pois as ajuda a serem inovadoras. Além disso, a abordagem do Design Thinking também está se tornando popular em ONGs, pois ajuda a desenvolver soluções melhores para os problemas sociais. Devido a sua característica de ser colaborativo, permite que soluções eficazes surjam de baixo para cima 
(BROWN; WYATT, 2010).

A IDEO propôs, em 2001, o modelo de Design Thinking chamado de 3 I's, que consiste em três etapas: inspiração; ideação; e implementação. Tim Brown, diretor executivo da IDEO, define-o como:

Existem três espaços para manter em mente: inspiração, ideação e implementação. Pense na inspiração como o problema ou a oportunidade que motiva a busca de soluções; ideação como o processo de gerar, desenvolver e testar ideias; e implementação como o caminho que leva da fase do projeto para a vida das pessoas (BROWN; WYATT, 2010, p.33, tradução livre).

Outros modelos também surgiram, como o diamante duplo, pela British Design Council, em 2005, o qual é definido como "o constante processo de expandir e refinar ideias presente nos projetos". Esse processo apresenta quatro etapas: descobrir, definir, desenvolver e entregar (ARAÚJO, 2017, p. 8).

O modelo Design Centrado no Humano (HCD) é o paradigma mais recente do Design Thinking, foi proposto em 2015 pela IDEO por solicitação de Bill e Melinda Gates e tem como foco processos de inovação social (PEZZINI, 2016).

Todos os modelos pautados no Design Thinking proporcionam um olhar com profundidade para as pessoas e problemas, humanizando o processo de inovação por meio da empatia, criando soluções de pessoas para pessoas e com pessoas (BACICH e MORAN, 2018).

\subsection{Design Thinking voltado à Educação}

Entendendo o Design Thinking como uma abordagem utilizável nos mais diferentes contextos, a IDEO lançou um toolkit intitulado Design Thinking para Educadores. No Brasil, o Instituto Educadigital, que já utilizava o Design Thinking desde 2010, fez a tradução do toolkit da IDEO para o português, e o disponibiliza gratuitamente em seu site: dtparaeducadores.org.

Especialmente projetado para que os educadores implementem o Design Thinking nas salas de aula, o toolkit divide a abordagem em cinco etapas: descoberta, interpretação, ideação, experimentação e evolução, mostrando como utilizar a abordagem do Design Thinking a partir dos desafios cotidianos que os educadores enfrentam (DT PARA EDUCADORES, 2014).

O presente trabalho utiliza o toolkit Design Thinking para Educadores, de autoria da IDEO e traduzido pelo Instituto Educadigital, como norte processual desta pesquisa, além da dissertação de mestrado de Rogério Lindo Fratin, intitulada Design Thinking aplicado à Educação, como referência de diagramação.

\section{3 À Procura da Escola}

Ao conversar com docentes, em diversas escolas do município de Laguna - SC, sobre a possibilidade de intervenção utilizando a abordagem do Design Thinking, a diretora de uma pequena escola, no bairro Ponta da Barra, mostrou-se particularmente interessada em um projeto a ser realizado no local. Alinhando as expectativas, ficou definido que essa seria a escola que receberia a intervenção.

Em uma reunião preliminar, a Diretora explicou que, na verdade, dentro do prédio da escola, existiam duas unidades educacionais: o Centro de Educação Infantil Meu Primeiro Passo e a Escola de Educação Básica Francisco Zezuíno Vieira, que compreendia o 2으으 ano e o 4ำ ano. Ela assume 
a direção em ambas as unidades.

Também relatou dos problemas que a escola enfrenta: a falta de funcionários, a sobrecarga em função do acúmulo de funções, os problemas estruturais, o possível fechamento da escola no ano que vem e os problemas de comunicação entre escola/pais/comunidade.

Após esse primeiro contato com a realidade da escola, foi marcado para a próxima manhã a etapa de imersão, para que, por meio da vivência da dinâmica escolar, pudessem-se elencar oportunidades para uma possível intervenção.

\section{Descoberta}

Durante os dias 22 e 23 de fevereiro, das 08 h00min às 17 h00min, aconteceu a etapa de imersão, doravante denominada Descoberta. Nos períodos matutino e vespertino, foram observadas as diferentes turmas que transitavam pelo pátio, cantina, corredores e salas de aulas. Poder observar as crianças e funcionários não só nas salas de aula, mas também em outros ambientes, permitiu uma visão holística e humana, imprescindível para a mentalidade empática necessária à abordagem do Design Thinking.

Devido à pouca idade dos alunos do Centro Educacional Infantil, ficou decidido que seria trabalhado apenas com os alunos da Escola, os quais se dividiam em dois períodos: matutino (no qual o 4 ano tem aula, sendo a sala do 4ㅇ ano não "mista", composta por cinco meninos e uma menina; vespertino (no qual são os alunos do $2^{\circ}$ e 3 o ano que têm as aulas em apenas uma sala, devido ao fato dessas turmas serem "mistas", totalizando 9 alunos em sala).

Nos momentos em que os alunos não estavam dentro da escola, hora do almoço e pósexpediente, aconteceram conversas com a Diretora e com a Professora Regente da escola. Outros funcionários poderiam ter acrescentado na melhor compreensão da realidade da escola, porém a opção de conversar apenas com a Diretora e Professora Regente era necessária devido ao quadro de funcionários estar muito reduzido naquele momento - a merendeira estava de licença e quem a está substituindo é a própria Diretora; é ela também que faz os trabalhos de orientação pedagógica, portaria, professor substituto, tesoureiro, e, por vezes, na área da limpeza, enquanto a Professora Regente ministra todas as aulas, com exceção das aulas de Educação Física, Inglês e Artes.

Com o intuito de entender melhor a realidade da escola, uma entrevista semiestruturada foi aplicada com a Diretora e a Professora Regente, na qual os problemas enfrentados pela escola foram descritos de forma mais detalhada. Assim, a seguir, tem-se uma condensação do que foi relatado pelos responsáveis da Escola.

A Diretora: Por ser uma escola de recursos escassos, a Diretora é sobrecarregada nas funções que, segundo ela: "devido à escola ser pequena, ela não recebe muita atenção da Secretaria da Educação". Ela reitera que existe um grande problema de comunicação entre a escola/pais/comunidade e que a comunidade cobra muito, porém, não dá o respaldo necessário para que a escola e o corpo docente atuem bem, dando como exemplo o fato do ginásio da escola estar fechado devido aos ventos fortes que quebraram algumas telhas: um problema que poderia ser resolvido rapidamente pela Secretaria da Educação ou pela comunidade, mas que, por falta de respaldo tanto de um como de outro, não aconteceu. $\mathrm{O}$ ginásio ficou, então, à mercê de muitas tempestades e, agora, apresenta problemas na estrutura e nas traves de futebol que oxidaram, por isso, tornou-se obsoleto. Ela também comentou sobre os computadores "pifados" e da biblioteca 
precária, a qual só passou a existir por esforço do corpo docente. A Diretora, por desempenhar diversos papéis na escola, foi uma importante fonte de informações sobre os alunos, a escola e a comunidade.

A Professora Regente: Ela conta que os alunos apresentam algumas dificuldades que já não condizem com as séries que cursam, e isso acontece "pois os alunos estão passando as séries sem estarem aptos", acarretando em dificuldades de seguir os cronogramas propostos às aulas. Entra em concordância com a Diretora ao relatar que um dos principais problemas é a relação dos pais/comunidade/escola, que não participam das atividades escolares, tendo de partir da escola ideias, para que os pais possam saber os dias que as crianças têm "dever de casa", por exemplo, incentivando a interação destes com as atividades escolares de seus filhos. A professora também comentou sobre a falta de concentração e de independência dos alunos, da necessidade de muitos feedbacks e de auxílio até para fazer as atividades mais simples como encontrar os cadernos das disciplinas corretas. Relatou de seu desejo de montar um blog e, assim, aproximar mais os alunos do uso da tecnologia como ferramenta de estudo, pois eles apenas utilizam os celulares e computadores para o lazer. Porém, comentou de sua dificuldade com as plataformas on-line e que, devido a isso, o blog não foi criado. A Professora Regente mostrou-se muito aberta e interessada com a pesquisa, porém adiantou que não poderia dar total autonomia, devido ao cronograma "apertado", e pediu para que o problema a ser trabalhado com o Design Thinking tivesse relação com seu plano de aula.

Então, conforme o Caderno de atividades do Design Thinking para Educadores (p. 4), foi feito um questionamento com as responsáveis, e as questões ora trabalhadas foram divididas nas sessões Sonhos e Pesadelos. Na primeira, a Diretora e a Professora Regente relataram o que gostariam que existisse na escola e, na segunda, o que poderia ser melhorado no local. As informações mais detalhadas, coletadas em entrevista com a Diretora e a Professora Regente, estão ilustradas na Tabela 1.

Tabela 1 - Sonhos e Pesadelos

\begin{tabular}{|l|l|}
\hline Sonhos/ Coisas que gostaria que existisse & Pesadelos/ Coisas que poderiam ser melhores \\
\hline Materiais escolares melhores & Falta de respaldo da Secretaria da Educação \\
\hline Móveis novos & Falta de material escolar \\
\hline Brinquedoteca & Abandono do Estado \\
\hline Secretaria da Educação mais presente & Salas mistas \\
\hline Mais alunos & Distância da comunidade \\
\hline Merendeira substituta & Ventiladores e cortinas com defeito \\
\hline Mais utilização dos jogos mindlab & Biblioteca precária \\
\hline Interação escola/comunidade & Falta de atenção dos alunos \\
\hline Ginásio de esportes reformado & Aulas de Ed. Física feitas em locais inadequados \\
\hline Utilização de tecnologia em prol dos estudos & Cronograma apertado \\
\hline
\end{tabular}

Fonte: Adaptado da Cartilha Design Thinking para Educadores (2014) 
Quanto aos alunos, foi observado, nas aulas do 40 ano, que as crianças têm muita necessidade de feedback, dificultando o progresso das aulas. Além disso, os alunos conversavam muito sobre jogos e vídeos da internet, causando dispersão. Assim, ficou evidente que eles são muito articulados nas questões de tecnologia e no vocabulário acerca dela, mas apresentam muitas dificuldades nas matérias aprendidas em sala de aula e em fixar os conteúdos aprendidos anteriormente. Chamaram a atenção, no processo, as dificuldades com os conteúdos sobre a Criação do Universo, segundo da teoria do Big Bang, de geolocalização e de leitura de mapas. Ademais, entender a divisão dos continentes e a das Américas também eram pontos de dificuldade dos alunos.

Já no período vespertino, nas aulas do $2 \% / 3$ ano, as dificuldades se concentravam no fato de a sala ser mista e os alunos terem diferentes graus de maturidade e conhecimento. A sala apresentava dificuldades em compreender o que é um substantivo; utilizar corretamente as letras maiúsculas e minúsculas; e, por não compreenderem bem os substantivos, compreender os adjetivos.

Essa primeira fase do projeto consistiu em entrar em contato com os stakeholders (partes interessadas) por meio da imersão e de uma conversa semiestruturada com a Diretora e a Professora Regente, com o intuito de listar os problemas que poderiam vir a serem trabalhados.

\section{Interpretação}

Após os dois dias de imersão, em nova conversa com a Diretora e a Professora Regente, os pontos de convergência foram a:

1- Falta de proximidade, por parte dos pais e da comunidade, das atividades escolares;

2- Falta de atenção dos alunos nas aulas;

3- Pouca autonomia dos alunos;

4- Falta de aulas que dialogassem com o universo de interesse dos alunos; e

5- Pouca utilização de recursos tecnológicos nas aulas.

Então, em reunião com a Professora, as demandas elencadas foram confrontadas com as perguntas: "Quais intervenções seriam possíveis de serem executadas?" e "Quais convergiam com o plano de aula da Professora?". Ao terminar essa análise, ficou determinado que a intervenção ocorresse na turma do 4ำ ano, por ser de alunos com um pouco mais de idade e por estarem tendo dificuldades interdisciplinares envolvendo as aulas de Geografia e História. O objetivo passou a ser, então, pautado no questionamento: "Como tornar os conteúdos de Geografia e História, do primeiro bimestre, mais interessantes?".

\subsection{8 de fevereiro - Reunião de Pais}

Ao acompanhar a reunião de pais, pôde-se averiguar que as queixas da Diretora e Professora Regente procediam no que se refere à comunidade cobrar da escola, porém não atuar junto a ela em prol das crianças. Nessa ocasião, foi explicada aos pais a importância de aulas mais dinâmicas; a necessidade de aproximação da escola com a comunidade; e as dificuldades que seriam trabalhadas acerca dos conteúdos de História e Geografia. Os pais mostraram-se receptivos, mas não houve perguntas, mostrando certa falta de engajamento com as atividades escolares. 


\section{Ideação}

Até essa etapa, um contato direto e formal com a sala do 40 ano ainda não havia acontecido, o qual veio a acontecer no dia 26 de fevereiro 2018. Nessa data, a abordagem do Design Thinking foi apresentada aos alunos como sendo um conjunto de métodos com a intenção de solucionar problemas com o foco no ser humano. Foi discutido também sobre as etapas previstas e sobre a que seria trabalhada naquele momento: a Ideação, que consiste na geração de ideias.

Antes de começar um brainstorming, os alunos montaram um semicírculo, em frente ao quadro, com o intuito de tornar o ambiente mais acolhedor, o que é imprescindível nesse processo. No livro Design Thinking, Ambrose e Harris postulam sobre como deve ser o processo de brainstorming:

[...] os participantes têm total liberdade para dar sugestões em um ambiente livre de críticas, o que encoraja a apresentação de ideias inusitadas e potencialmente úteis. Recursos como flip charts e quadros brancos podem ser usados para facilitar o processo e registrar as ideias geradas (AMBROSE; HARRIS, 2011, p. 65)

Além disso, o quadro foi dividido em algumas partes para melhor organizar as ideias que iriam surgir. O brainstorming foi iniciado com perguntas sobre o que os alunos gostavam de fazer em casa. Estes prontamente responderam que gostavam de jogos no computador, videogame, vídeos no YouTube, assistir desenhos animados, entre outras atividades. Foi solicitado, então, aos alunos que escrevessem isso em post-its e os colassem em uma das divisões feitas no quadro. Perguntas mais específicas acerca das respostas foram feitas, como quais eram os canais do YouTube que eles assistiam e três deles se destacaram: AM3NIC, AUTHENTIC GAMES e MINGUADO. Todos eram dedicados a gameplays do jogo MineCraft, sendo este o mais jogado entre os alunos. Ainda em conversa, foi perguntado aos alunos se eles utilizavam a plataforma para estudar, eles disseram nunca ter utilizado com tal finalidade. Apenas um deles afirmou que utilizava o Google às vezes, e os demais estudavam apenas utilizando o material didático oferecido pela escola.

Os desenhos mais assistidos entre os alunos são: Bob Esponja, Hora de Aventura e Steven Universe. Eles têm em comum o fato de serem em 2D e também por estarem disponíveis na internet.

No processo de brainstorming (conforme Figura 1), sugestões como a produção de jogos de computador e tabuleiro foram feitas, mas a de produzir vídeos para internet que ganhou mais votos, convergindo com a vontade expressa dos alunos de se tornarem youtubers. Alinhando ao plano de aula da Professora Regente, tratando-se do gênero Documentário, ficou decidido que um vídeo seria feito para o YouTube e um canal para a escola seria criado. No vídeo, os alunos deveriam explicar os conteúdos aprendidos nas aulas de Geografia e História até o presente momento. Por sugestão dos próprios alunos, o documentário deveria conter animações que o tornasse mais dinâmico e atraente para os outros e para os próprios alunos. 


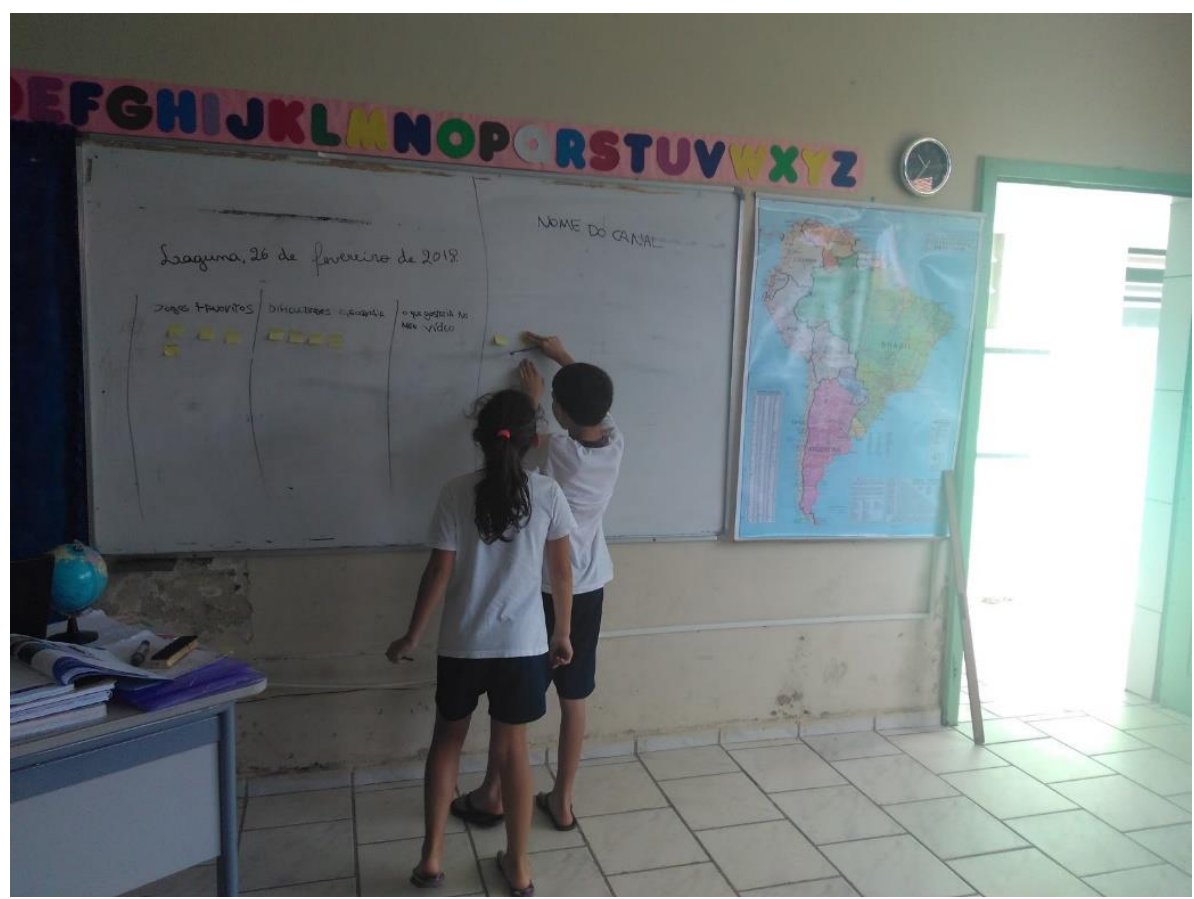

Fonte: Elaborado pelo autor

Para que o documentário pudesse ser feito, foi realizado, de maneira colaborativa, um roteiro. Dessa forma, ficou definido que se começaria com a apresentação conceitual do Big Bang, relatar-se-ia sobre a formação dos Continentes e, depois, dar-se-ia uma explicação sobre a noção de divisão das Américas e localização do Brasil, Santa Catarina e Laguna, respectivamente. Após essa definição, os alunos foram chamados para realizar uma atividade de Caça-ao-Tesouro, que tinha a intenção de fazer com que compreendessem a importância do estudo dos mapas.

\subsection{Caça-ao-Tesouro}

$\mathrm{Na}$ atividade de Caça-ao-Tesouro, proposta no processo, os alunos deviam encontrar uma caixa de chocolate escondida na escola e, para isso, contaram com a ajuda de um mapa previamente feito, onde o X marcava o local do tesouro. Primeiramente, os alunos foram instruídos sobre a localização deles no mapa. Após encontrarem a caixa, por sugestão dos alunos, ela foi novamente escondida. Porém, dessa vez, os alunos não teriam um mapa. A brincadeira repetiu-se mais duas vezes, nas quais as crianças agiram de forma totalmente autônoma. Dividiram-se em dois grupos e determinaram que, enquanto um grupo escondia a caixa, o outro deveria ficar dentro de uma sala de aula e esperar sua vez de procurar e vice-versa. Ao término dessa dinâmica de Caça-ao-Tesouro, uma roda de conversa foi aberta para que fosse debatida a importância de se ter um mapa na hora de encontrar algo. Traçando um paralelo com a realidade dos alunos, também foi lembrado que a leitura de mapas é muito importante em jogos de computador e de console, pois em diversos deles é pelo mapa que o jogador é guiado para seus objetivos dentro do jogo. Dessa forma, ficou evidente que, quando se tem um mapa, há mais facilidade em localizar-se e identificar áreas.

A Figura 2 mostra a leitura do mapa feita pelos alunos, no momento da dinâmica de Caça- 
ao-Tesouro, ministrado na Escola. Neste momento, os alunos estavam tentando achar sua localização para assim poder começar a caçada.

Figura 2 - Alunos fazendo a leitura do mapa na dinâmica Caça-ao-Tesouro

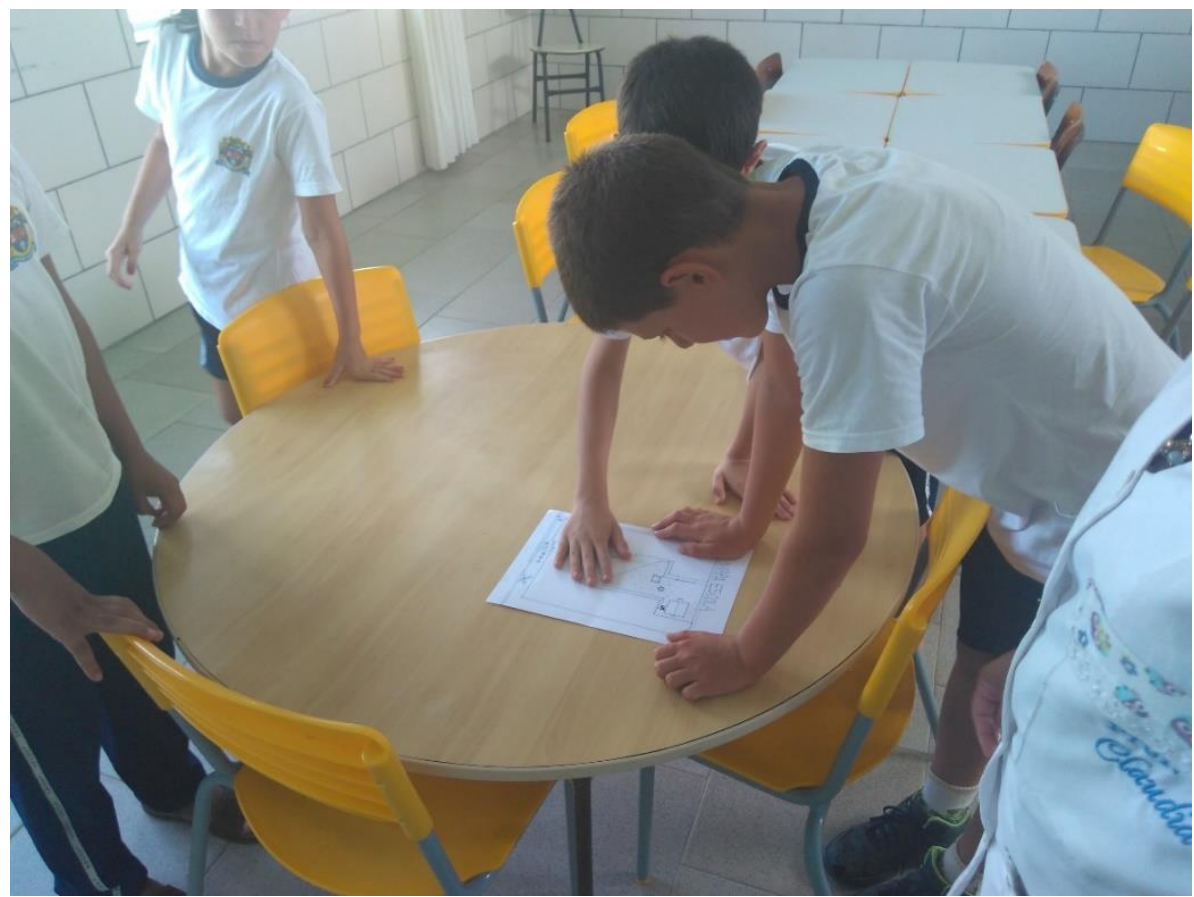

Fonte: Elaborado pelo autor

Os alunos, após a dinâmica proposta, mostraram-se mais acessíveis e confiantes em desenvolver as próximas atividades, pois observaram que seriam agentes ativos da ação de aprender, diferente das aulas tradicionais expositivas, nas quais os alunos são agentes passivos. Isso contribuiu positivamente no andamento do projeto e na interação do grupo.

\subsection{Nova conversa com a Professora Regente}

Conversando sobre os resultados obtidos no brainstorming e na atividade de Caça-aoTesouro, a Professora Regente sugeriu que os conteúdos das aulas de Ciências sobre A Origem e Evolução da vida, segundo a teoria de Charles Darwin, fossem incluídos no documentário, pois isso auxiliaria no entendimento holístico da cadeia de eventos que se iniciou no Big Bang e que culminou em espécies complexas como a nossa, a homo sapiens. O objetivo desse trabalho, então, passou a ser "Como tornar as aulas de Ciências, Geografia e História mais atraentes ao passo de se promover a proximidade da escola com a comunidade?". Nessa conversa, também ficou decidido que os alunos teriam que assistir mais aulas sobre A Origem e Evolução da vida, antes de gravarem o documentário, para ter uma boa desenvoltura nos conteúdos filmados.

\section{Experimentação}

\subsection{Identificando Necessidades}

Com o objetivo de colaborar com as aulas da Professora Regente e melhorar a compreensão dos alunos sobre a divisão dos Continentes e das Américas e a localização do Brasil e de Santa Catarina no Mapa-múndi, foi elaborado um Mapa-múndi em E.V.A, inspirado na dinâmica de blocos 
do jogo MineCraft, no qual cada continente tinha uma cor e era uma peça independente. Este foi utilizado em uma dinâmica na biblioteca da escola. Por meio dele, foi possível que os alunos visualizassem com mais facilidade a divisão dos Continentes, além de conseguirem observar que o Continente Americano é apenas um - representado pela cor verde na Figura 3 -, entretanto, divido em três peças, e que essa divisão é feita para melhor compreensão dos estudos acerca do Continente.

Concomitante, conteúdos sobre A Origem e Evolução da vida foram expostos aos alunos por intermédio de animações previamente selecionadas pela Professora Regente. O primeiro foi retirado da série original intitulada Cosmos, do físico Carl Sagan; o segundo, de uma abertura do desenho animado Os Simpsons, no qual o personagem Homer passa por todos os estágios da Evolução. Dessa forma, os alunos tiveram, de maneira mais didática e descontraída, um embasamento sobre o conteúdo, podendo visualizar graficamente como que provavelmente ocorreu todo o processo de Evolução e ter a noção de que muitas das espécies que já habitaram esse planeta já não existem mais.

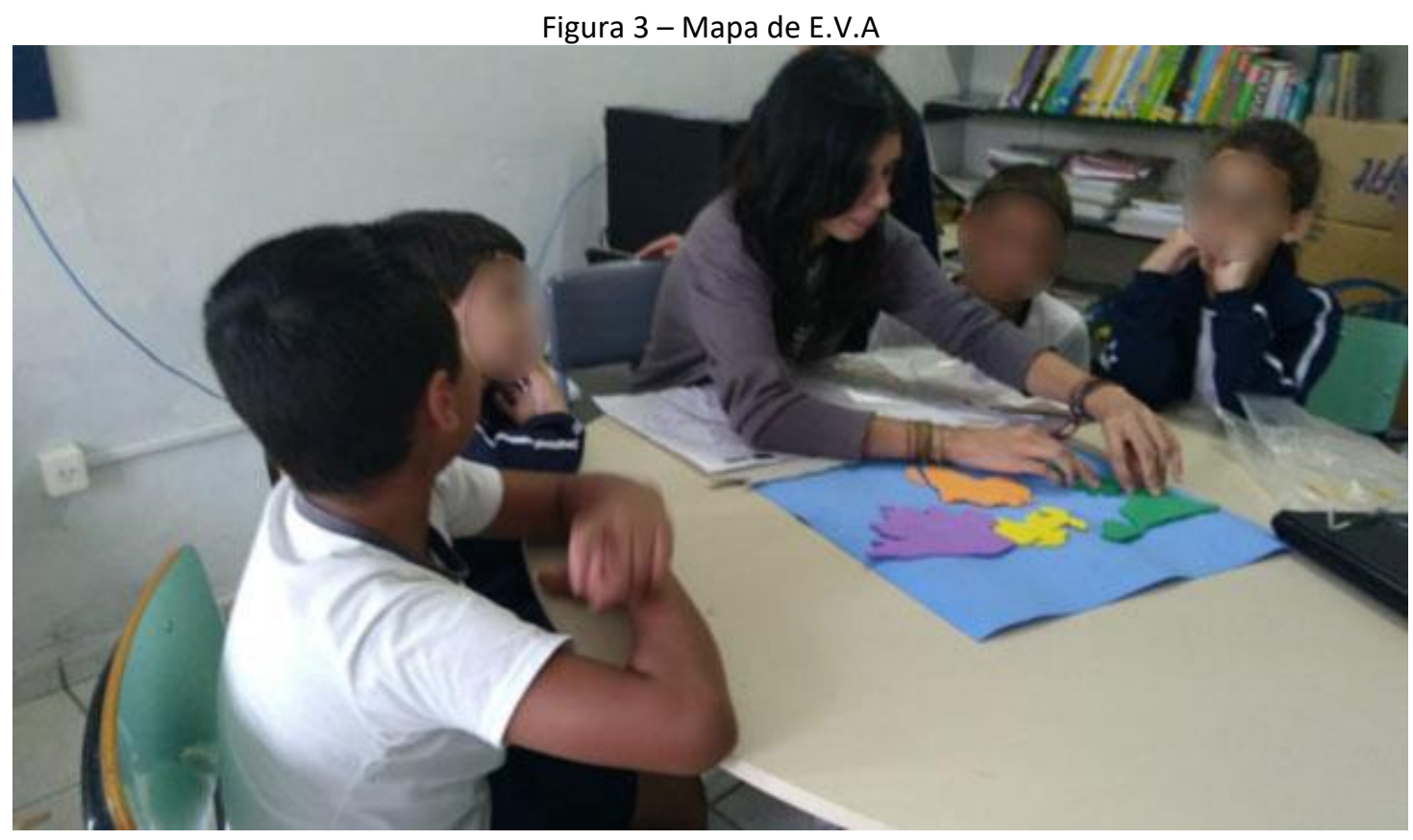

Fonte: Elaborado pelo autor

Por diversas vezes, os alunos foram estimulados a falar sobre como imaginavam que todos esses processos haviam acontecido, a questionarem de onde vieram e para onde vão, culminando em conversas que tinham o intuito de chamar os alunos ao questionamento concernente ao conteúdo proposto. Giordan e Vecchi (1996) afirmam, no livro As Origens do Saber, que é por meio do questionamento que o aprendente extrai conhecimento, sendo ele uma importante fonte para o avanço da aprendizagem, pois incita os alunos a irem além de seu estágio atual e buscarem por novas e criativas soluções.

Mais tarde, nesse mesmo dia, o roteiro foi novamente debatido. Dessa vez, agregando as sugestões da Professora Regente e definindo que, no documentário, o conteúdo exposto daria início com o Big Bang, passaria pela Pangeia, localizaria o Brasil e Santa Catarina no mapa, depois 
abordaria sobre A Origem e Evolução da vida, e concluiria com a noção de que a evolução ainda não terminou. Assim, um roteiro semiestruturado foi montado, no qual os alunos definiram, entre eles, quais as cenas que cada um gostaria de gravar. Ficou decidido, também, que o roteiro seria gravado de forma linear e que todos estariam presentes no momento das gravações. Além disso, os alunos não teriam de gravar totalmente de acordo com o roteiro, mas, sim, explicar, com suas palavras, sobre os conteúdos propostos nas cenas.

\subsection{Começo das Gravações}

Os primeiros testes de gravação foram feitos. Neles, foi descartada a possibilidade de gravar sem tripé, visto a pouca estabilidade focal da câmera que seria utilizada. A possibilidade de gravar com mais pessoas na sala também foi descartada, pois isso dificultaria a concentração de quem estava sendo filmado. Além disso, a opção de gravar apenas com um roteiro semiestruturado teve a intenção de evitar que os alunos apenas repetissem mecanicamente o conteúdo selecionado, dando autonomia para que utilizassem seu próprio repertório e vocabulário para a construção das cenas, tornando-o assim mais autêntico. Afinal, o processo de internalização do conhecimento não acontece de forma mecânica e não está limitado à repetição, mas é um processo criativo que depende de conhecimentos anteriores e da construção de sentidos para a produção de novos conhecimentos (ALVES, 2007).

No dia 8 de março, as cenas começaram a ser gravadas. A Professora Regente não pôde ceder todas as aulas, então, um aluno por vez foi levado até outro ambiente, no qual havia sido montado um cenário, com tripé, cadeira e mapa. Nesse momento, foi conversado com cada aluno, para que eles ficassem menos ansiosos em serem filmados. O conteúdo de cada cena foi repassado e os alunos utilizaram suas palavras para explicar o conteúdo em cada uma delas. Nesse dia, nem todas as cenas puderam ser gravadas no período matutino, então, a escola providenciou que os alunos do 40 ano comparecessem também no período vespertino, para todas as cenas serem gravadas. Enfim, durante o dia 13 de março, cenas de establishment shot foram filmadas na escola e, com isso, as gravações foram concluídas.

\subsection{Edição e Animação}

Feitas as gravações, concentra-se na edição, a qual é inspirada na dinâmica das salas de aula, na qual os professores costumam escrever questionamentos no quadro e os alunos têm de responder de forma oral ou escrita. Ressalta-se que esse tipo de edição permitiu que o vídeo tivesse maior fluidez na transição das cenas.

As explicações dos alunos foram intercaladas com animações que ilustram o que está sendo mencionado na explicação por parte do aluno. Elas foram feitas em 2D, assim como as que os alunos gostam de ver na televisão, e tiveram como referência as animações da série Cosmos, de 1980. Quanto à produção das animações, primeiramente, elas foram desenhadas coloridas e tinham uma estética característica de animações genéricas feitas em flash, que foram modificadas e culminaram em uma estética que coincide com a dos cards de perguntas que servem de transição entre as cenas (Figura 4). Essa escolha estética faz com que as animações aparentem ser feitas em um quadronegro, trazendo a temática da sala de aula. 
Figura 4 - Comparação da estética da animação inicial e final

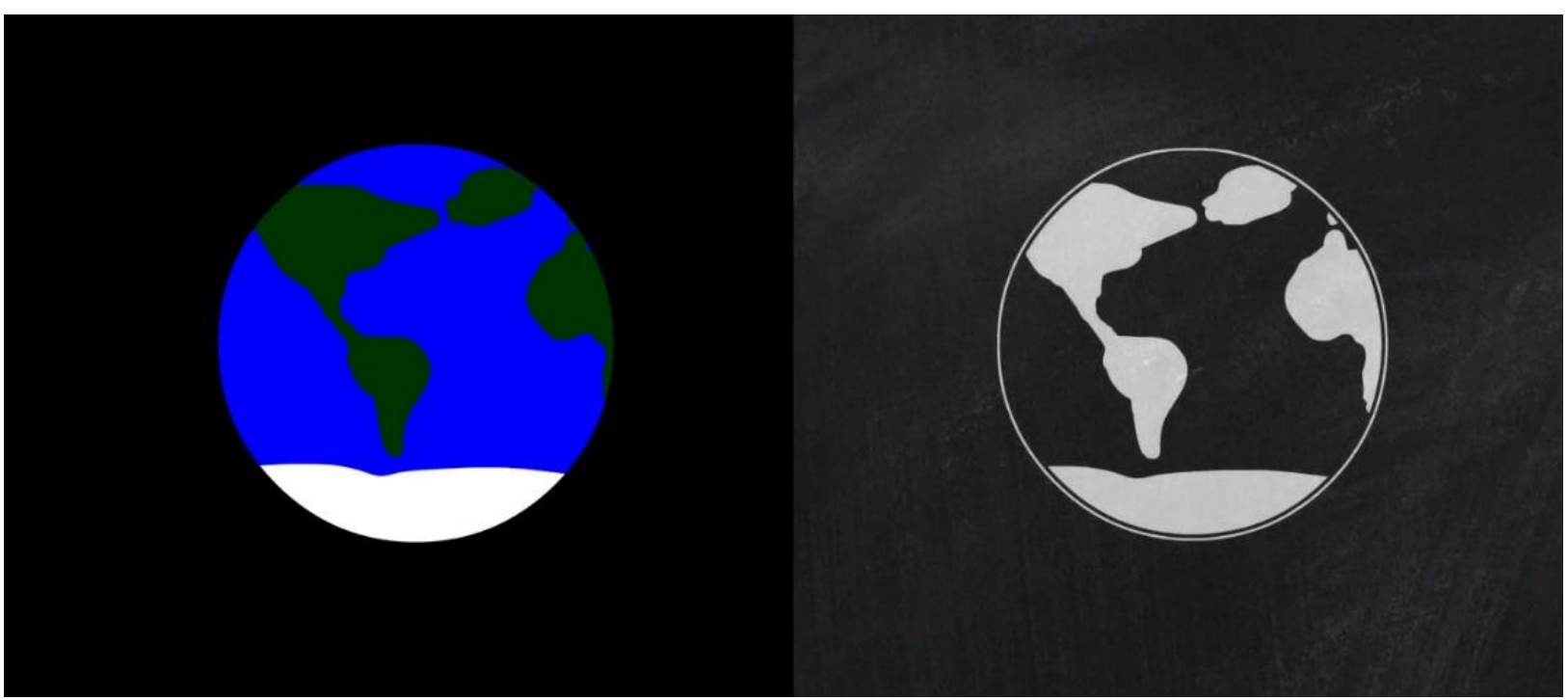

Fonte: Elaborado pelo autor

Efeitos sonoros foram inseridos nas animações para dinamizar o vídeo e criar ambientação, pois eles reforçam o que está sendo visto. Todos os efeitos foram encontrados em bancos gratuitos na internet, o que facilitou o trabalho, pois poupou o tempo de produção. Quanto à trilha, é de Scott Holmes e se chama Happy Days, também encontrada em bancos gratuitos.

\section{Evolução}

Em conversas prévias, a Professora Regente havia manifestado seu interesse em ter um blog, para que os alunos utilizassem a internet para fins educativos. Visto isso, somado à necessidade de maior integração com escola/comunidade, um blog foi aberto, na plataforma gratuita WIX; e um template gratuito foi escolhido para o blog, com o objetivo de proporcionar um ambiente clean e de fácil usabilidade, para que os alunos e professora pudessem utilizar sem grandes dificuldades. $O$ vídeo documentário produzido com os alunos do 4ㅇa ano foi postado no blog, no endereço: https://eebfranciscozezuin.wixsite.com/fzvblog. O documentário está no canal do YouTube E.E.B. Francisco Zezuíno Vieira, no endereço: https://www.youtube.com/watch?v=frRDcP-oTzl, criado para que os alunos possam postar os futuros trabalhos produzidos em vídeo.

Nesse projeto, alguns vídeos foram criados no formato de tutorial, funcionando como um toolkit, para auxiliar a Professora Regente e os alunos a navegarem e postarem, promovendo a autonomia em seus projetos futuros.

A partir do mês de abril, a escola passou a contar, no corpo docente, com uma Professora de Informática, que também ficou encarregada de auxiliar a Professora Regente e os alunos a alimentarem o blog (print do blog na Figura 5) e o canal do YouTube. Com a Professora de Informática, todos os caminhos para a utilização de ambas as plataformas foram revisados, a fim de mostrar como as plataformas funcionam. Ficou combinado que as dúvidas quaisquer que eventualmente pudessem surgir, nas futuras postagens, seriam sanadas por meio de conversas em 
plataformas como Skype, telefone ou em futuras visitas à escola. O toolkit para a utilização do blog e do canal também foi repassado à Professora de Informática.

Figura 5 - Print do site da escola
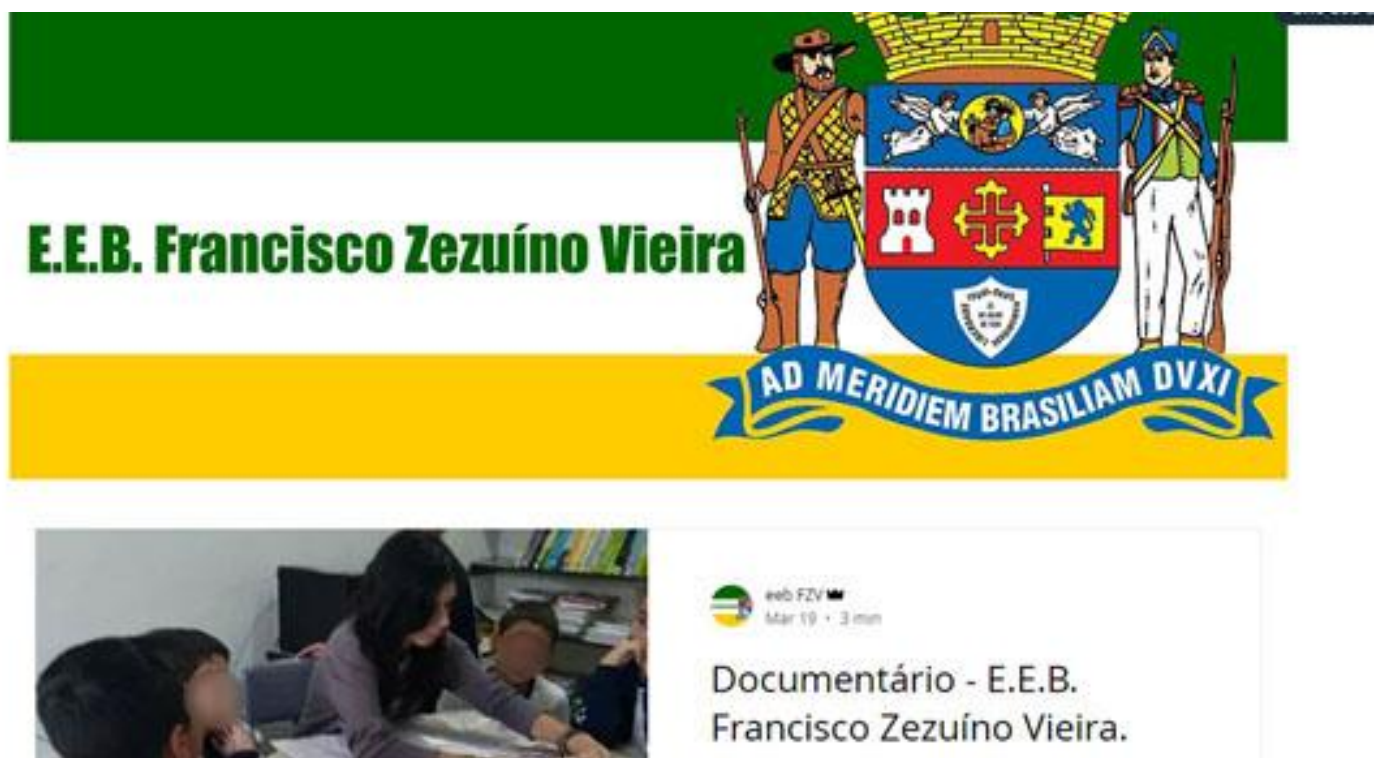

\section{Documentário - E.E.B.}

Francisco Zezuíno Vieira.

Fonte: Elaborado pelo autor

\subsection{Indicadores de Sucesso}

Conforme a Tabela 2, os indicadores de sucesso utilizados foram os views no YouTube e blog, autonomia dos alunos e da Professora Regente no uso das ferramentas nesses meios de comunicação e a condição da utilização das ferramentas em projetos futuros. Além disso, o objetivo de atingir a comunidade, por meio de todo o processo ministrado na escola, foi alcançado.

Tabela 2 - Indicadores de Sucesso

\begin{tabular}{|l|l|}
\hline Views no YouTube & 55 views \\
\hline Views no Blog & 9 views \\
\hline Autonomia no uso das ferramentas (blog e canal no YouTube) & Sim \\
\hline Utilização das ferramentas em projetos futuros & Sim \\
\hline Atingiu a comunidade e/ou pais & Sim \\
\hline
\end{tabular}

Fonte: Elaborado pelo autor

No canal do YouTube, o vídeo já conta com cerca de 55 visualizações em poucos dias, sendo grande parte delas feitas por pais e pela comunidade, fato que foi confirmado pela Diretora da escola e que, com certeza, é um indicador de sucesso, pois mostra que a comunidade teve interesse no conteúdo produzido pelos alunos. Espera-se que o canal, assim como o blog, continue 
funcionando como ferramentas de aprendizado e de integração da comunidade com a escola, na promoção de aulas mais dinâmicas mais próximas à realidade e aos interesses dos alunos.

\section{Considerações Finais}

O Design Thinking mostrou-se uma abordagem poderosa para a investigação e solução de problemas no ambiente escolar, capaz de encontrar soluções viáveis para problemas complexos e interdisciplinares em um período de tempo e com recursos limitados. Com a utilização dessa abordagem, a dinâmica usual das aulas é quebrada e, por meio de um trabalho coletivo, soluções podem ser encontradas e trabalhadas, buscando um alinhamento dos interesses dos alunos com suas necessidades de aprendizado. Assim, por meio do processo dividido em cinco etapas (descoberta, interpretação, ideação, experimentação e evolução), foi possível compreender que os alunos do 40 ano estavam com dificuldades interdisciplinares que envolviam as aulas de Ciências, História e Geografia; e que os conteúdos dessas matérias se interligavam e poderiam ser trabalhados juntos. $O$ entendimento sobre os interesses pessoais dos alunos em seus momentos de lazer ajudou no desenvolvimento da solução que visou a alinhar desejos e necessidades dos alunos e da Professora Regente.

A utilização do recurso audiovisual mostrou-se interessante e eficaz na sala de aula, visto a familiaridade dos alunos com vídeos produzidos para a internet, em plataformas como o YouTube, e o interesse que esse tipo de conteúdo gera. Isso acarreta, também, na possibilidade de utilizar esse recurso na educação como uma forma dinâmica para transmitir conteúdos e para inserir o uso da tecnologia na sala de aula de maneira fácil e economicamente viável. A criação do blog proporcionou um ambiente virtual organizado para que as atividades escolares sejam postadas e compartilhadas com os pais dos alunos e com a comunidade, atuando na promoção da integração entre estes. Assim, os objetivos propostos foram sendo alcançados à medida que os alunos foram se mostrando engajados com as dinâmicas, bem como se percebeu o envolvimento da comunidade e dos pais, propósito determinado pelas responsáveis da Escola, por meio do feedback, pelo número das visualizações do blog e do canal no YouTube.

Espera-se que a utilização da abordagem do Design Thinking seja cada vez mais difundida nas salas de aula, assim como a promoção do toolkit, da IDEO, Design Thinking para Educadores. Porém, há que se ressaltar a necessidade de, e sugere-se, então, que o toolkit seja adaptado à realidade das escolas brasileiras - desafio esse para os designers que se debruçam sobre a problemática da educação -, visto que a versão em português é apenas uma tradução do toolkit original da IDEO, que foi originalmente pensado com base na realidade das escolas estadunidenses. 


\section{Referências}

ALVES, M.F. Da repetição para a aprendizagem: desenvolvimento cognitivo por meio da interação. Verdades online - Ensino - 2/2007, p. 41-57.

ARAUJO, A.P. Como o Design Thinking Contribui no Processo de Inovação de uma Instituição Financeira. UniCEUB, 2017.

AMBROSE, G; HARRIS, P. Design Thinking. Porto Alegre: Bookman, 2011.

BACICH, L.; MORAN. J. (Org.). Metodologias ativas para uma educação inovadora: uma abordagem teórico-prática. Porto Alegre: Penso, 2018.

BROWN, T; WYATT, J. Design Thinking for Social Innovation. Stanford Social Innovation review. 2010, p. 31-35.

GIORDAN, A.; VECCHI, G. de. As Origens do Saber: das concepções dos aprendentes aos conceitos científicos. Traduzido por Bruno Charles Magne. 2. ed. Porto Alegre: Artes Médicas, 1996.

IDEO. Design Thinking para Educadores. In: Design Thinking para Educadores. Disponível em: http://www.dtparaeducadores.org.br/site/.

LOCKWOOD, T. Design Thinking: Integrating Innovation, Customer Experience, and Brand Value. New York: Skyhorse Publishing, Inc, 2010.

PEZZINI, M.R. Contribuições do Design Centrado no Humano para o Projeto do Mobiliário Doméstico em Apartamentos Compactos. Tese (Doutorado em Arquitetura e Urbanismo), Programa de Pós-graduação em Arquitetura e Urbanismo - Universidade Federal de Santa Catarina. Florianópolis, 2016, p. 244. 